\title{
O PAPEL DA ENFERMAGEM E A FORMAÇÃO DE MULTIPLICADORES ANTE O PROCESSO DE PREVENÇÃO À RECAÍDA
}

\author{
Marilene Gonçalves França ${ }^{1}$; \\ Marluce Miguel de Siqueira ${ }^{2}$
}

\begin{abstract}
A prevenção à recaída consiste em ensinar o indivíduo a identificar as situações de risco e a lidar com elas. Objetivou-se, nesta pesquisa, qualificar a consulta de enfermagem prestada ao indivíduo que enfrenta o processo de recaída, através da integração ensino/ assistência, no Programa de Atendimento ao Alcoolista. Pesquisa descritiva e exploratória, qualiquantitativa, com análise de conteúdo, dividida em três fases: confecção do manual, formação da equipe de enfermagem e avaliação. O estudo possibilitou observarem-se mudanças nas concepções dessa equipe acerca da recaída, da relação entre a teoria e a prática e de sua atuação como mediadora desse processo educativo.
\end{abstract}

Descritores: Alcoolismo; Recidiva; Enfermagem; Educação em Saúde.

\footnotetext{
${ }^{1}$ Enfermeira, Secretaria Municipal de Vitória, ES, Brasil. E-mail: leninhamgf@yahoo.com.br.

2 Enfermeira, Doutor em Ciências Fisiológicas, Professor Associado, Departamento de Enfermagem, Centro de Ciências da Saúde, Universidade Federal do Espírito Santo, Vitória, ES, Brasil. E-mail: marluce.siqueira@ufes.br.
} 


\section{THE ROLE OF NURSING AND THE FORMATION OF MULTIPLIERS IN RELAPSE PREVENTION}

Relapse prevention involves teaching individuals to identify and cope with risk situations. In this research, the goal was to qualify nursing consultations for individuals going through the relapse process through nursing/care integration, in the "Care Program for the Alcoholic". A descriptive and exploratory, qualitative-quantitative approach with content analysis was used, divided into three phases: preparation of the manual, nursing staff training and evaluation. The study revealed changes in this team's conceptions of relapse, the relation between theory and practice and its performance as a mediator in this educational process.

Descriptors: Alcoholism; Recurrence; Nursing; Health Education.

\section{El PAPEl de LA ENFERMERÍA Y LA FORMACIÓN DE MULTIPLICADORES EN EL PROCESO DE PREVENCIÓN DE LA RECAÍDA}

La prevención de la recaída abarca enseñar a las personas a identificar y hacer frente a situaciones de riesgo. La finalidad en esa investigación fue cualificar la consulta de enfermería al individuo que pasa por el proceso de recaída, a través de la integración enseñanza-atención, en el "Programa de Atención al Alcohólico". Se trata de un estudio descriptivo y exploratorio, cualitativo y cuantitativo, con análisis de contenido, dividido en tres fases: preparación del manual, formación del personal de enfermería y evaluación. El estudio permitió cambios en las concepciones del equipo acerca de la recaída, la relación entre la teoría y la práctica y su papel como mediador del proceso educativo.

Descriptores: Alcoholismo; Recurrencia; Enfermería; Educacíon em Salud.

\section{Introdução}

O alcoolismo é uma das enfermidades mais frequentes no mundo. Nas últimas décadas, vem se transformando em grave problema de saúde pública. Dentre as maiores dificuldades encontradas nos programas de tratamento do alcoolismo, o alto índice de recaídas é um dos principais motivos de falta e abandono de tratamento ${ }^{(1)}$. Aproximadamente, de acordo com a literatura, de 50 a $60 \%$ dos alcoolistas apresentavam recaídas nos primeiros meses após o tratamento ${ }^{(2)}$.

Para tentar reduzir os índices de recaídas e de insucessos no tratamento de alcoolismo, vários foram os modelos propostos no passado. Atualmente, aquele que tem recebido maior ênfase é o denominado modelo cognitivo comportamental ${ }^{(2)}$, que ajuda o paciente a examinar a forma particular como ele constrói e entende seu mundo e o auxilia a experimentar novas maneiras de se relacionar melhor com todos os aspectos da vida.
Sabe-se que os comportamentos adictivos (como a dependência do álcool e outras drogas) são definidos como padrões de hábitos adquiridos, que podem ser modificados com a aplicação de procedimentos de novo aprendizado. Os indivíduos podem aprender a mudar e a aceitar a responsabilidade pessoal por sua própria recuperação. $\mathrm{O}$ processo de mudança de hábitos envolve pelo menos três estágios distintos: compromisso e motivação (preparação para a mudança), implementação da ação da mudança comportamental específica (por exemplo, cessação do uso de drogas) e manutenção desse comportamento em longo prazo ${ }^{(2)}$.

A prevenção da recaída é um programa de tratamento que conscientiza a pessoa no sentido de antecipar situações que a coloquem em risco para a recaída, possibilitando-lhe preveni-las, modificá-las, enfrentá-las, ou seja, aprender a lidar com tais situações ${ }^{(3)}$. É importante, também, compreender os fatores determinantes do retorno do 
alcoolista à bebida, e saber utilizar tais informações para reduzir as taxas de recaída. Esse é um dos primeiros passos no desenvolvimento e implementação dos tipos de estratégias de prevenção à recaída ${ }^{(2)}$.

É imprescindível, no entanto, que, nesse processo, ocorra a motivação para a mudança, isto é, o estado de prontidão ou vontade de mudar como estratégia fundamental para a continuação no novo comportamento, uma vez que a motivação permeia todo o processo de mudança. No intuito de compreender como as pessoas mudam, foi desenvolvido o Modelo Transteórico ${ }^{(4)}$, que descreve a prontidão para mudar como estágio de mudança pelo qual o indivíduo transita. Esse modelo está baseado na premissa de que a mudança comportamental é um processo, e que as pessoas têm diversos níveis de motivação e de prontidão para mudar ${ }^{(5)}$.

Nesse contexto, a educação em saúde tem papel relevante, pois, ao se falar de educação, fala-se de articular conhecimentos, atitudes, comportamentos e práticas pessoais que possam ser compartilhados com a sociedade. $\mathrm{O}$ que se quer dizer é que o processo educativo favorece o desenvolvimento da autonomia, ao mesmo tempo em que atende os objetivos sociais ${ }^{(6)}$.

Como resultado dessa constatação, recentemente, a enfermagem passou a utilizar o referencial sociocultural na formação de recursos humanos para a educação de pacientes, na tentativa de possibilitar ensino e assistência alicerçados em um processo de conscientização, cuja concepção de ensino/aprendizagem esteja fundamentada nos pressupostos da educação transformadora, que tem como centro a formação de consciência crítica, possibilitadora da reflexão sobre a prática profissional e sobre o compromisso com a sociedade ${ }^{(7)}$. Considerandose que o enfermeiro não pode intervir em uma realidade, sem prescindir de teoria capaz de fornecer elementos para que a sua intervenção atinja os fins por ele propostos, pretendeu-se, neste estudo, qualificar a abordagem ao indivíduo situado em processo de recaída, através da integração ensino/assistência na consulta de enfermagem do Programa de Atendimento ao Alcoolista (PAA), a fim de contribuir para a manutenção da abstinência alcoólica e para a mudança do seu estilo de vida.

\section{Metodologia}

Trata-se de pesquisa descritiva e exploratória, com abordagem qualiquantitativa, tendo como base a teoria cognitiva comportamental ${ }^{(2)}$ e a motivacional ${ }^{(4)}$. O estudo teve como cenário o Programa de Atendimento ao Alcoolista, devido à sua proposta de trabalho interdisciplinar dirigido a alcoolistas e seus familiares, que inclui a adoção de metodologia assistencial participativa e conscientizadora $^{(8)}$. O trabalho foi estruturado em três fases. Na primeira fase, foi realizada a confecção do Manual de Prevenção à Recaída para ser utilizado durante a consulta de enfermagem. Visando dar subsídio a essa construção, realizou-se revisão teórica sobre o tema "prevenção da recaída", na base de dados da BIREME e BDENF, abrangendo o período de 2000 a 2005, além da utilização de periódicos especializados, livros e manuais educativos. Assim, foram delineadas as quatro áreas de abrangência do manual: a) conceito de prevenção da recaída, b) instruções para a prevenção da recaída, c) atividades para a prevenção da recaída e d) onde buscar ajuda. Depois, ocorreu a produção propriamente dita do manual educativo Projeto Viva Vida - uma experiência de prevenção: o que você precisa saber sobre prevenção da recaída?, com a elaboração dos textos educativos e ilustrados. Logo após, realizou-se uma aplicação piloto do manual em alcoolistas ingressantes no tratamento ambulatorial do PAA-HUCAMUFES, para a familiarização com o referido material e sua validação . A segunda fase consistiu na formação da equipe de enfermagem do PAA, visando o desenvolvimento de competências teórico-práticas para abordagem à prevenção da recaída. A formação ocorreu na forma de seminários teóricos, com discussão grupal, divididos em quatro módulos: a) sensibilização, b) processo de recaída, c) prevenção à recaída e d) estratégias de prevenção à recaída. Cada módulo teve a duração de dez horas aula. Os encontros foram quinzenais. Na terceira fase, ocorreu a avaliação da equipe de enfermagem em dois momentos: inicial, a fim de identificar a percepção da equipe acerca da temática prevenção à recaída, e, final, para identificar as mudanças decorrentes da formação.

O questionário utilizado na etapa inicial (préformação) era composto de duas partes - identificação dos sujeitos e percepções acerca da prevenção à recaída. Após os esclarecimentos sobre o estudo e mediante assinatura do termo de consentimento livre e esclarecido, os participantes responderam ao instrumento. Foram construídos quadros ilustrativos para facilitar os procedimentos de agrupamento, de categorização, de análise e de interpretação dos dados. No segundo momento (pós-formação), foi realizado o grupo focal ${ }^{(9)}$ para avaliar os benefícios advindos da formação. O grupo teve a duração de, aproximadamente, uma hora, com participação da equipe de enfermagem do PAA, que havia recebido a formação de prevenção à recaída.

Em virtude da natureza do estudo e em conformidade com a técnica de grupo focal, a seleção da amostra foi proposital. A pauta foi dividida em dois temas: o primeiro, relacionado ao conteúdo do treinamento, e o segundo, com os benefícios advindos da formação. $\mathrm{O}$ grupo foi conduzido por um moderador e contou com a participação de um observador. Além das anotações do observador, os depoimentos foram gravados, utilizandose dois gravadores, dispostos adequadamente em relação à distribuição dos participantes, a fim de se obter gravação nítida e abrangente; depois, os discursos foram transcritos, cuidadosamente, na íntegra.

$\mathrm{Na}$ análise dos dados, foi realizada a leitura das transcrições e destacada a fala referente aos benefícios consequentes à formação. Com isso, definiram-se as categorias temáticas que, posteriormente, foram analisadas. Recorreu-se à análise de conteúdo ${ }^{(10)}$, com base no referencial teórico proposto, utilizando-se o tema como unidade de registro, e buscando organizar os dados em categorias temáticas. 
A pesquisa foi estruturada observando-se os preceitos éticos da Resolução n¹96/96, do Conselho Nacional de Saúde (CNS), aprovado pelo Comitê de Ética do CSS da UFES $\left(n^{\circ} .079 / 07\right)$.

\section{Resultados}

Perfil dos participantes integrantes da equipe de enfermagem

A amostra foi constituída por dez participantes: nove estudantes de graduação em enfermagem e uma enfermeira. O perfil da clientela mostrou que $70 \%$ dos participantes se encontravam na faixa etária de 20 a 30 anos, seguido de $<20 \operatorname{anos}(20 \%)$. Quanto à distribuição, segundo o nível de instrução, verificou-se que $90 \%$ dos estagiários possuíam nível superior incompleto, isto é, encontravam-se no quinto período $30 \%, 40 \%$ no sexto, $10 \%$ no quarto e $10 \%$ no terceiro período. Apenas um indivíduo (10\%) com mais de 20 anos de graduação em enfermagem tinha idade entre 40 e 50 anos. Segundo a etnia, observou-se que a maior parte dos indivíduos se denomina branca (60\%), seguida dos pardos $(30 \%)$ e apenas $10 \%$ são negros. A maioria dos indivíduos declarou ser católica (50\%), espírita (30\%) e protestante (20\%). Quanto à distribuição da amostra, segundo o estado civil, detectou-se número significativo de solteiros (90\%), sendo apenas $10 \%$ casados. No que se refere ao tempo de atuação no PAA, observou-se que a maioria relatou seis meses de atuação na consulta de enfermagem (60\%), seguida pelas atuações de sete a doze meses $(20 \%)$, treze a dezoito meses $(10 \%)$ e mais que dezoito meses $(10 \%)$.

\section{Formação da equipe de enfermagem}

Os participantes, antes da formação, consideravam que o conceito de recaída estava ligado ao padrão de consumo exercido pelo indivíduo, quando ele retornava ao seu antigo comportamento (50\%). Nessa fase, algumas respostas foram confusas e demonstraram insegurança quanto ao conceito do que é a recaída (20\%). Contudo, após a formação, o conceito de recaída mostrou-se muito mais elaborado e mais conciso, tanto quando se menciona que a recaída é o retorno ao uso da substância após o período de abstinência (50\%) quanto quando é considerado o retorno ao consumo de álcool, no mesmo padrão ou superior a ele $(50 \%)$. E, ainda, foi mencionada a recaída como momento de aprendizado, para que o indivíduo possa elaborar estratégias de prevenção (10\%).

No que tange à diferença entre o conceito de lapso e recaída, as respostas mostraram-se satisfatórias e bem elaboradas $(70 \%)$. Entretanto, alguns desconheciam a diferença entre as duas situações referidas (10\%). Nota-se que, depois da formação, todos os participantes perceberam a diferença entre lapso e recaída.

Quanto à percepção do lapso e recaída durante o tratamento, apenas $20 \%$, consideravam o lapso e a recaída como elementos que fazem parte do processo de tratamento; outros 20\% reconheceram que eles servem como motivos para continuar o tratamento, não se devendo considerá-los como fracasso. Esse aspecto é preocupante, quando acompanhado de outros dois tipos de respostas (20\%): quando a recaída é vista como descrença e, ainda, quando relatam que o tratamento não está sendo eficaz.

Os motivos relacionados aos conflitos interpessoais (discussões, discordâncias, brigas, ciúme etc.) foram predominantes $(80 \%)$, seguidos pelos associados à pressão social $(70 \%)$, estados emocionais negativos (60\%) e aqueles relacionados aos estados físico-fisiológicos negativos $(50 \%)$. Posteriormente à formação, os motivos explicitados pelos participantes mantiveram-se bem variados; porém, uma diferença significativa foi quanto aos motivos referentes aos estados físico-fisiológicos negativos, passando de $50 \%$ antes da formação e diminuindo para $20 \%$ depois.

Quando questionados, inicialmente, se conheciam alguma teoria sobre a prevenção à recaída, 70\% dos participantes relataram não conhecer esse tipo de teoria, sendo que apenas $10 \%$ fizeram referência à teoria motivacional. Após a formação, quando questionados novamente se conheciam alguma teoria de prevenção à recaída, $100 \%$ dos entrevistados responderam que conheciam. A partir desse conhecimento, ao serem perguntados sobre a motivação no processo de recaída, a maioria dos participantes (40\%), considerava essencial a motivação para o indivíduo manter-se abstinente, ou, ainda, como atitude positiva para a efetividade do tratamento $(20 \%)$. Por outro lado, $20 \%$ consideraram que a falta de motivação é fator predisponente para a recaída. Talvez, por isso, a motivação percebida pelos participantes como essencial para que o indivíduo alcance a abstinência apresentou aumento de 40 para $75 \%$.

Quanto ao conceito de prevenção à recaída, $40 \%$ das respostas consideraram a prevenção à recaída como um conjunto de estratégias para enfrentar as situações de risco. Por outro lado, outros $40 \%$ entendem a prevenção da recaída ao conhecer e prevenir os motivos que levam a ela. E, ainda, $10 \%$ das respostas citaram um conjunto de ações que visam contribuir para a manutenção da abstinência alcoólica.

Após a formação, quando questionados se colocavam em prática alguma estratégia de prevenção à recaída, 90\% responderam sim e apenas $10 \%$ disseram não. Nota-se que $55,5 \%$ dos participantes mencionaram o uso do manual de prevenção à recaída, como estratégia colocada em prática. Por outro lado, 22,2\% fizeram referência à orientação sobre os fatores de risco que levam à recaída, bem como outros 22,2\% utilizam o aconselhamento como técnica para que os indivíduos evitem as situações de risco.

Após a formação, verificou-se que os participantes se referiram novamente ao aconselhamento (12,5\%), atividades substitutivas do comportamento de risco $(12,5 \%)$ e técnicas motivacionais $(12,5 \%)$ como estratégias de enfrentamento da recaída e seus antecedentes. Outros fizeram referência a estratégias cognitivas comportamentais $(12,5 \%)$ e a técnicas para mudanças de estilo de vida $(12,5 \%)$.

Os participantes apontaram mudanças no conceito de prevenção à recaída, ao relatarem que, apesar de conhecerem o conceito, a visão da recaída se expandiu, 
de modo a se compreender o processo de forma mais complexa, como pode ser observado no seguinte relato:

[...] acho que conceito de recaída a gente já tinha desde o nosso ingresso no PAA eu acho que aqui a gente aprendeu, meio que evoluiu nosso conceito, ampliou a nossa visão (P1).

É importante salientar que os trechos das falas dos participantes destacados durante a transcrição das falas, que ocorrem durante o grupo focal, são apresentados, aqui, codificados através da letra "P" que indica o participante, seguida pelo algarismo arábico, para diferenciar um participante do outro.

Quanto ao enfrentamento da recaida pelos técnicos, os participantes relataram dificuldades para lidar com a recaída durante o tratamento, às vezes atribuindo a culpa a si mesmos ou à intervenção proposta. Dessa maneira, enfrentavam a recaída como um fracasso pessoal ou do tratamento, o que pode ser expresso na fala a seguir. [...] um paciente teve uma recaída. Eu fiquei superchateada com isso, não sei por que gerou um sentimento assim muito controverso. Eu fiquei seca assim, muito nervosa, não sei por que, e assim é aquela coisa, você não pode trazer a culpa para si (P2). No entanto, após a formação, os participantes passaram a entender que a recaída é evento comum durante o tratamento, e que ela pode se tornar um elemento facilitador do processo de recuperação, a partir do momento em que serve como suporte para a aprendizagem e reflexão para a adoção de novas atitudes, como pode ser visto no relato a seguir. [...] agora a gente compreende a recaída como parte do tratamento e, a partir daquilo dai, inclusive, é que ele vai conseguir tomar uma decisão mais forte, entendeu? Um aprendizado (P3).

Quanto à importância de reconhecer os antecedentes da recaída, os participantes relataram que uma das dificuldades encontradas é não ter conhecimento sobre o que pode levar um indivíduo ao retorno do comportamento de uso e abuso do álcool, isto é, sobre os antecedentes que provocam o lapso ou a recaída, como exemplificado neste relato. Às vezes a gente não enxerga isso no tratamento, às vezes o paciente teve uma recaída e você não consegue identificar qual mesmo foi o fator que levou ele a ter a recaída ou lapso (P4).

Após a formação, os participantes perceberam que são vários os fatores de risco que podem levar à recaída, não somente os determinantes interpessoais, mas também os intrapessoais, como pode ser observado a seguir. No meu caso, a contribuição foi mais a parte da teoria e das terapias aplicada à prevenção a recaída, foi a que mais contribui, pra mim, sabe? Porque eu, talvez, o meu olhar contemplava muito a parte externa, algumas coisas, conflitos internos, sentimentos, emoções, crenças, valores eu não contemplava assim, nos pacientes, não tanto. Eu via mais o quê relacionamentos familiares, coisas externas, que poderiam contribuir, ambiente, seja lá o que for, cultura, mas a parte interna mesmo, eu não tinha esse olhar tão crítico assim (P4).

Outro benefício apontado pelos participantes é quanto à importância de se aliar a teoria à prática, de modo que a primeira possa subsidiar a segunda, para melhor vivência da prática. [...] eu achei que foi muito rico, porque às vezes a gente tá usando no serviço a terapia cognitiva comportamental só que você não tá percebendo que é. Porque, às vezes, a gente acha que está fazendo o melhor, o melhor, mas nossa, como uma teoria, um modelo teórico é fundamental na nossa na vivência na assistência (P5).
A compreensão do processo de mudança foi mencionada como benefício da formação, uma vez que um comportamento aprendido pode demandar tempo e esforço para ser modificado, como exemplificado na fala a seguir. [...] eu acho que foi importante, de participar desse curso, porque eu pude aprender como é difícil os passos para chegar à abstinência, entendeu? Como é difícil essa a mudança de comportamento do individuo mesmo e quando você entende esse processo inicial, você passa a ver a recaida realmente como parte do processo, pelo fato de ser realmente dificil mudar um hábito de que você tem durante anos e ano (P6).

A formação possibilitou aos participantes avaliarem sua prática na assistência de enfermagem. Relataram que esse novo aprendizado possibilitará nova postura quando do retorno ao atendimento. [...] eu acredito que com esse curso, vem trazer coisas novas pra gente, tá? Com certeza, gera o desejo de mudar a assistência que a gente realiza lá. Não que tá ruim, mas a gente tem condições de melhorar. $O$ curso mostrou isso (P5).

Após terem participado da formação, os participantes compreenderam que a sua responsabilidade é elemento facilitador no processo de mudança, e que o próprio indivíduo é quem deve assumir a responsabilidade pela modificação de seu comportamento, como pode ser observado no relato a seguir. O profissional tem que levar $o$ paciente a reconhecer que a responsabilidade édele, levá-lo, tanto pelo que ele se cumpriu no tratamento, as metas estabelecidas, a responsabilidade dele pela manutenção ou não da abstinência, os riscos que podem trazer pra ele as consequências disso. E mostrando pra ele que a responsabilidade é dele. Ele tem o poder de decisão de continuar ou não, mas o profissional tem que estar do lado pra ajudar ele nesse processo do tratamento (P6).

\section{Discussão}

Neste estudo, observou-se o predomínio dos participantes situados na faixa etária de 20 a 30 anos (70\%), nível superior incompleto (90\%) e solteiro (90\%). Esses dados se justificam porque a maioria (90\%) dos participantes é composta por alunos de graduação, cursando o ensino superior, o que corrobora os achados do $\mathrm{IBGE}^{(11)}$. Em relação ao tempo de atuação no PAA, percebeu-se que a maioria relatou seis meses de atuação na consulta de enfermagem (60\%). Esse fato se dá graças à realização de um "rodízio", no referido programa, pelos acadêmicos de enfermagem do PAA, de modo a permitir que sua atividade de extensão não prejudique a sua formação acadêmica, ao mesmo tempo que permite ao aluno atuar no desenvolvimento de atividades de ensino/ assistência, pesquisa e extensão.

Os dados obtidos acerca da formação da equipe de enfermagem revelam que a falta de entendimento mais profundo, ou mesmo complexo, do que é o processo de recaída na dependência química, é fator que pode influenciar no processo de recuperação do adicto.

No presente estudo, alguns participantes (20\%) demonstraram insegurança quanto ao conceito de recaída; no entanto, após a formação, as percepções demonstraramse mais elaboradas e mais concisas, corroborando os conceitos de vários autores ${ }^{(12-13)}$, ao considerarem a recaída como um processo no qual o alcoolista, em recuperação, 
volta a ingerir a mesma quantidade ou mesmo quantidades maiores, após um período de abstinência ou, ainda, quando a recaída é vista como um evento complexo, que acontece por uma série de processos cognitivos, comportamentais e afetivos, vistos como ponto crítico, a partir do qual o indivíduo pode retornar à abstinência ou desenvolver completo padrão de recaída, dependendo da forma como enfrenta tal episódio ${ }^{(2)}$.

Quanto ao enfrentamento e à diferença entre o lapso e recaída durante o tratamento, pôde-se observar que, após a formação, todos os participantes compreenderam a distinção entre os dois processos e sua importância, ao perceberem que o lapso corresponde a uma ingesta alcoólica relativamente menor, em relação à que ocorria antes do início do tratamento, além de se referir a um ato de beber inicial, esporádico, um deslize, "escorregão", que podem ocorrer com o alcoolista durante o tratamento. Tal fato é relevante, pois essa diferença é imprescindível para a abordagem ao alcoolista, já que a forma como o indivíduo conceitua e enfrenta o lapso pode determinar se ele será seguido ou não por uma recaída. Após ter sido enfatizado que a recaída e o lapso são comuns durante o tratamento e que precisam ser desmistificados, pois “[...] não se trata de queda do estado de graça, mas sim de um comportamento que precisa ser entendido objetivamente"(14), muitos participantes mudaram seu discurso, passando a considerar a recaída como parte do tratamento ou, ainda, como uma oportunidade de aprendizado. Tal fato é mencionado, porque as "taxas de insucessos" podem deixar os profissionais da saúde com a impressão de impotência pessoal e baixa eficácia, o que leva, amiúde, ao desenvolvimento, por parte do profissional, de expectativa de "imodificabilidade" do indivíduo alcoólico ${ }^{(2)}$.

Dentre os motivos que levam à recaída, destacam-se os relacionados aos estados físico-fisiológicos negativos que passaram de $50 \%$ antes da formação, diminuindo para $20 \%$ depois. Esse fato é relevante, porque os profissionais da saúde devem considerar, além do fator biológico, que também tem a sua relevância na dependência, as relações que o indivíduo estabelece com o meio e com as outras pessoas. Alguns autores ${ }^{(2,12)}$, visando diminuir a probabilidade de uma recaída, ressaltam a necessidade de identificação dos determinantes intrapessoais e interpessoais que a antecedem, já que esses são vistos como fatores de risco na percepção de autoeficácia do indivíduo.

Em relação ao conceito de prevenção à recaída, é preciso ressaltar que as respostas apresentam restrição, no sentido de se compreender os fatores que fazem com que o indivíduo evite o uso da substância ou, ainda, que se mantenha abstinente. Não foi feita nenhuma menção à mudança de estilo de vida. Entretanto, pode ser visto que o entendimento sobre o que é a prevenção à recaída se ampliou, após a formação, porque alguns participantes fizeram referência não só às estratégias para evitar a recaída, mas também a mudanças de hábitos de vida do indivíduo $^{(3,15)}$.

As estratégias utilizadas como recurso de enfrentamento correlacionam as estratégias de prevenção à recaída ${ }^{(2)}$. No entanto, apenas $11,1 \%$ dos participantes referiram-se às técnicas motivacionais. Considerando-se que a motivação é estratégia fundamental no processo de mudança, tal índice é considerado baixo, já que é primordial que o indivíduo assuma a responsabilidade pela sua mudança durante o tratamento, e isso é conhecimento essencial para o profissional de saúde que atua junto aos alcoolistas.

Os participantes declararam, antes da formação (70\%), não conhecerem nenhuma teoria voltada ao tratamento da dependência química. Esse é um dado relevante, já que as teorias servem para embasar as intervenções em saúde e melhorar a assistência pretendida. Outro fato relevante é que apenas 10\% fizeram referência à teoria motivacional, o que é de se estranhar, já que avaliar a motivação para mudança, independentemente do tratamento utilizado, parece ser aspecto importante para a utilização de intervenções adequadas às necessidades dos pacientes ${ }^{(4)}$. Nessa perspectiva, a relação teoria/prática não pode ser vista de maneira isolada e separada, mas deve ser entendida como uma relação de complementaridade, no sentido de a teoria fundamentar a competência necessária e suficiente para o exercício e a realização da prática.

A maioria dos participantes (40\%) considerava essencial a motivação para o indivíduo manter-se abstinente, outros julgavam que a falta de motivação é fator predisponente para a recaída $(20 \%)$. Tais achados justificam-se, pois a aderência ao tratamento depende da motivação do indivíduo, já que abandonar o uso de uma substância está por demais ligado a uma série de comportamentos aos quais a motivação está vinculada $^{(16)}$.Por essa razão, a motivação, que era percebida pelos participantes como essencial para que o indivíduo alcance a abstinência, apresentou aumento de 40 para $75 \%$, dado relevante que caracteriza o câmbio de visão sobre o processo de mudança, uma vez que o indivíduo precisa estar motivado para querer mudar. $\mathrm{O}$ entendimento do processo de mudança foi ressaltado como benefício da formação, já que o comportamento adquirido pode ser modificado com a aplicação de procedimentos de novo aprendizado, o que possibilitará modificações no estilo de vida do indivíduo, de forma lenta e gradual ${ }^{(2)}$.

Outros benefícios advindos da formação foram acerca da mudança da conduta profissional, e do papel de facilitador no processo de mudança, uma vez que a intervenção numa realidade exige redefinição da ação do profissional, e implica novas proposições conceituais, metodológicas, ideológicas e práticas, a fim de se atingir tal propósito $^{(7)}$. Nessa perspectiva, a educação libertadora ${ }^{(17)}$ baseia-se nessa prática transformadora, que estabelece uma forma crítica e consciente de pensar e atuar em busca da transformação dos saberes existentes. O indivíduo, então, "sai da posição de paciente" e torna-se capaz de assumir a responsabilidade pelas modificações indispensáveis para a prevenção da recaída e reabilitação existencial, passando a ser agente de seu processo terapêutico ${ }^{(3)}$. Dessa forma, o profissional deve aprender a considerar o indivíduo como sujeito do processo educativo, em busca de sua autonomia e da participação na elaboração de propostas educativas ${ }^{(18)}$. 


\section{Considerações finais}

Pensar em qualificar a assistência de enfermagem, na abordagem da prevenção à recaída, possibilitou aos participantes reverem suas concepções acerca do processo acima mencionado, incluindo a relação existente entre a teoria e a prática e a sua atuação como mediadores desse processo educativo. Ao se investigar as contribuições da formação para os participantes, foram identificados benefícios relacionados ao conhecimento adquirido e também mudanças de atitudes em relação à sua prática. Outro fato que foi mencionado é o papel do enfermeiro, que deve atuar como facilitador do processo de mudança, ao mostrar para o sujeito a possibilidade que ele tem de recomeçar, e incentivá-lo a fim de que ele encontre motivos para trilhar um novo caminho. Ao concluir este estudo, compreende-se a importância da realização de outras pesquisas nessa proposta de investigação, que possibilitem maior entendimento quanto à construção dos saberes dos profissionais de saúde, que precisam ser colocados em prática nas suas relações sociais. Saberes esses que precisam ser avaliados e reconstruídos no cotidiano do desenvolvimento profissional.

\section{Referências}

1. Siqueira MM, Garcia MLT, Souza RS. O impacto das faltas às consultas em um programa de dependentes de álcool. J Bras Psiquiatria. 2005;54(2):114-9.

2. Marlatt GA, Gordon JR. Prevenção à recaída: estratégia e manutenção no tratamento de comportamentos adictivos. Porto Alegre (RS): Artes Médicas; 1993. 524 p.

3. Knapp P. Prevenção à recaída. In: Ramos SP, Bertolote JM, Campana AAM, Gruber AC, Woitowitz AB, Andrade AG, Neumann BG, Galperim B, et al. Alcoolismo hoje. $3^{\mathrm{a}}$ ed. Porto Alegre (RS): Artes Médicas; 1997. p. 173-96. 4. Prochaska JO, Diclemente C. Transtheorical therapy: toward a more integrative model of change. Psycother Theory, Res Pract. 1982;20:161-73.

5. Oliveira MS, Laranjeira R, Araujo RB, Camilo RL, Schneider DD. Estudo dos estágios motivacionais em sujeitos adultos dependentes do álcool. Psicol Reflexão Crítica. 2003;16 (2):265-70.

6. Ministério da Educação (BR). Secretaria de Educação Fundamental (BR). Parâmetros Curriculares Nacionais. Brasília; 1997.

7. Nakatani AYK. Processo de enfermagem: uma proposta de ensino através da pedagogia da problematização [dissertação]. Ribeirão Preto (SP): Escola de Enfermagem de Ribeirão Preto da Universidade de São Paulo; 2000.

8. Macieira MS, Gomes MPZ, Garcia MLT. Programa de Atendimento ao Alcoolista do HUCAM da UFES (PAAHUCAM-UFES). J Bras Psiquiatria. 1993;42(2):97-109.

9. Gatti BA. Grupo Focal em Ciências Sociais e Humanos. Brasília: Líber Livro; 2005. 77 p.

10. Bardin L. Análise de conteúdo. Lisboa: Edições 70; 1977. $281 \mathrm{p}$.

11. IBGE (Fundação Instituto Brasileiro de Geografia e Estatística). Censo Demográfico de 2000. [acesso 8 out 2007]. Disponível em: http://www.ibge.gov.br/censo/.

12. Silva EA, Ferri CP, Formigoni MLOS. Situações de recaída em pacientes dependentes de álcool e outras drogas durante o tratamento: um estudo preliminar. J Bras Psiquiatria. 1995; 44(6):311-5.

13. Büchele F, Marcatti, M, Rabelo DR. Dependência química e prevenção à "recaída". Texto \& Contexto Enferm. 2004;13(2):233-40.

14. Edwards G, Marshall EJ, Cook CCH. O tratamento do alcoolismo: um guia para profissionais da saúde. $4^{\mathrm{a}}$ ed. Porto Alegre (RS): Artmed; 2005. 242 p.

15. Figlie NB, Bordin SL, Laranjeira R. Aconselhamento em Dependência Química. São Paulo (SP): Roca; 2004.

16. Jungerman FS, Laranjeira R. Entrevista motivacional: Bases teóricas e práticas. J Bras Psiquiatria 1999;48(5):197-207.

17. Freire P. Pedagogia do Oprimido. 17 ed. Rio de Janeiro: Paz e Terra; 1987. 213 p.

18. L'abbate S. Educação em saúde: uma nova abordagem. Cad Saúde Pública. 1994;10 (4):481-90.

\section{Como citar este artigo:}

França MG, Siqueira MM. O papel da enfermagem e a formação de multiplicadores ante o processo de prevenção à recaída. SMAD, Rev. Eletrônica Saúde Mental Álcool Drog. (Ed. port.). maio-ago. 2011 [acesso:

Disponível em:

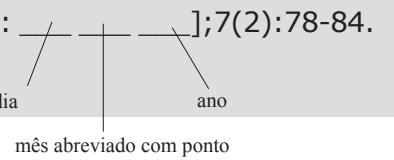

